06

\title{
Особенности углеродных нанотрубок, синтезированных из метана и ацетилена при использовании катализатора $\mathrm{FeCl}_{3}$
}

\author{
(C) А.Г. Редина, ${ }^{1}$ М.В. Авраменко, ${ }^{1}$ Н.В. Лянгузов ${ }^{1,2}$ \\ ${ }^{1}$ Физический фракультет, Южный фредеральный университет, \\ 344090 Ростов-на-Дону, Россия \\ ${ }^{2}$ Федеральный исследовательский центр Южный научный центр РАН, \\ 344006 Ростов-на-Дону, Россия \\ e-mail: avramenko.marina@gmail.com
}

Поступило в Редакцию 4 июня 2020 г.

В окончательной редакции 2 октября 2020 г.

Принято к публикации 6 октября 2020 г.

\begin{abstract}
Сравнены структурные особенности углеродных нанотрубок, синтезированных на одной установке методом каталитического химического осаждения из газовой фазы при использовании двух разных углеродсодержащих прекурсоров и катализатора $\mathrm{FeCl}_{3}$. В качестве углеродсодержащих прекурсоров применялись метан и ацетилен. Хлорид железа наносился на подложки кремния путем высушивания на их поверхности капли водного раствора. Исследовалось влияние вариации температуры и давления на процесс синтеза. Полученные образцы исследованы с помощью сканирующей электронной микроскопии и спектроскопии комбинационного рассеяния света. Установлена нелинейная связь температуры синтеза со степенью дефектности синтезированных углеродных нанотрубок. Показано влияние типа углеродсодержащего прекурсора на морфологию синтезируемых образцов углеродных нанотрубок.
\end{abstract}

Ключевые слова: многостенные углеродные нанотрубки, каталитическое химическое осаждение из газовой фазы, сканирующая электронная микроскопия, спектроскопия комбинационного рассеяния света.

DOI: $10.21883 /$ JTF.2021.03.50524.193-20

\section{Введение}

Уже более 30 лет углеродные нанотрубки (УНТ) и их разнообразные и уникальные физико-химические свойства активно изучаются учеными со всего мира. Эти новые материалы можно использовать в различных гибких и поддающихся механическому растяжению устройствах, включая аккумуляторы и конденсаторы, солнечные элементы, сенсоры, тонкопленочные транзисторы, дисплеи и многое другое [1-3]. Вследствие высокого аспектного отношения материалы, образованные УНТ, могут иметь различную структурную организацию как по диаметру и/или хиральности нанотрубок (величине их разброса), так и по их упорядоченности (от материалов с произвольной плотностью и ориентацией нанотрубок до волокон и упорядоченных массивов УНТ) [1-3]. В частности, наиболее разупорядоченные материалы, образованные УНТ самых разных диаметров и хиральностей, производятся в форме порошков и используются для усиления композитных материалов, изготовления литий-ионных батарей, проводящих чернил и тонкопленочных транзисторов для гибких электронных устройств, а также при разработке технологий защиты от электромагнитного излучения [4]. Более упорядоченные материалы, имеющие меньший разброс по диаметрам и хиральностям УНТ, могут быть основой для высококачественных композитных материалов, различных полупроводниковых устройств и сенсоров [4]. Разумеется, каждое конечное применение диктует свои специфические требования к характеристикам материала, образованного УНТ, и, как следствие, к технологиям его синтеза. По этой причине многие научные группы ведут работы по оптимизации режимов синтеза УНТ, стремясь достигнуть наилучшего соотношения между стоимостью производства УНТ и их качеством, требуемым для конкретных применений.

Одним из наиболее популярных методов получения УНТ на сегодняшний день является каталитическое химическое осаждение из газовой фазы [5], который в отличие от своих исторических предшественников разрядно-дугового метода и лазерной абляции [6] позволяет использовать более низкие $\left(\sim 350-1000^{\circ} \mathrm{C}\right)$ температуры синтеза. Также рассматриваемый метод более удобен, поскольку возможность одновременного варьирования его многочисленных параметров (среди которых химический состав углеродсодержащих прекурсоров и восстановителей, их парциальные давления и фоновое давление в камере синтеза, способы доставки прекурсоров в зону реакции, геометрия реакционного объема, термические режимы, внешние электростатическая и индукционная активации) практически не ограничена [5]. Более того, в рамках данного метода легко реализуется возможность пространственного позиционирования точек зарождения УНТ с помощью нанесения катализаторов роста различными (в том числе литогра- 
фическими) способами. И хотя за последние годы в развитии рассматриваемого метода синтеза УНТ был достигнут определенный прогресс (в частности, удалось понизить температуру роста УНТ до $350^{\circ} \mathrm{C}$ с использованием железа в качестве катализатора [7], вырастить ориентированные массивы сверхдлинных (до $1 \mathrm{~mm}$ ) УНТ [8], а также значительно сузить разброс УНТ по хиральностям за счет использования биметаллических катализаторов [9]), установить четкие и однозначные связи между физико-технологическими режимами синтеза УНТ, их реальной структурой и кинетикой роста все еще не удалось, что только подогревает интерес ученых.

Физико-химические свойства углеродсодержащего прекурсора (УСП) определяют диапазон необходимых температур и давлений, возможные катализаторы, а также целый ряд других параметров каталитического химического осаждения УНТ из газовой фазы [5]. Поэтому переход от одного УСП к другому в рамках даже одной и той же экспериментальной установки может представлять собой нетривиальную задачу. Для практических приложений важно, чтобы при таком переходе менялось минимальное количество параметров синтеза, а качество и количества получаемых УНТ сохранялось. В настоящей работе мы предлагаем очень простой вариант метода синтеза УНТ как из метана, так и из ацетилена. Хлорид железа (III), осажденный на кремниевую подложку в виде капли водного раствора, использовался как катализатор. В рамках данного метода и выбранного сочетания прекурсоров мы провели серию экспериментов, изменяя в широких пределах параметры синтеза УНТ. Полученные образцы были исследованы при помощи спектроскопии комбинационного рассеяния света (КРС), а также сканирующей электронной микроскопии (СЭМ).

\section{1. Экспериментальная часть}

Синтез УНТ был выполнен методом каталитического химического осаждения из газовой фазы [5] на собственной установке кафедры „Нанотехнология“ физического факультета Южного федерального университета. В качестве каталитического прекурсора был использован $0.01 \mathrm{M}$ водный раствор хлорида железа (III), осаждаемый в виде капли на кремниевые подложки ориентации (111), которые после высыхания были размещены в кварцевой трубе. Процедура синтеза проводилась с использованием метана или ацетилена в качестве углеродсодержащего прекурсора, водорода как газавосстановителя и аргона как буферного газа (применяемого во время нагрева и охлаждения печи). Данные газы и каталитический прекурсор были выбраны в силу их доступности, метод нанесения каталитического прекурсора удобен своей простотой. Применялось быстрое помещение подложки с катализатором в разогретую до нужной температуры зону реакционного объема с уже уста-
Основные параметры синтеза образцов

\begin{tabular}{|c|c|c|c|c|c|c|}
\hline \multirow{3}{*}{ № } & \multirow{3}{*}{ УСП } & \multicolumn{5}{|c|}{ Параметры фазы синтеза } \\
\hline & & \multirow{2}{*}{$T,{ }^{\circ} \mathrm{C}$} & \multicolumn{2}{|c|}{ Потоки газов, sccm } & \multirow{2}{*}{ Давление, Torr } & \multirow{2}{*}{ Время, min } \\
\hline & & & УСП & $\mathrm{H}_{2}$ & & \\
\hline$M_{1}$ & \multirow{9}{*}{$\mathrm{CH}_{4}$} & 1050 & 100 & 200 & \multirow{5}{*}{760} & \multirow{5}{*}{60} \\
\hline$M_{2}$ & & 1000 & 100 & 200 & & \\
\hline$M_{3}$ & & 975 & 100 & 200 & & \\
\hline$M_{4}$ & & 950 & 100 & 200 & & \\
\hline$M_{5}$ & & 925 & 100 & 200 & & \\
\hline$M_{6}$ & & \multirow{4}{*}{950} & 50 & 50 & 10.0 & \multirow{3}{*}{10} \\
\hline$M_{7}$ & & & 40 & 40 & 6.3 & \\
\hline$M_{8}$ & & & 30 & 30 & 4.0 & \\
\hline$M_{9}$ & & & 10 & 10 & 1.6 & \multirow{2}{*}{60} \\
\hline$A_{1}$ & \multirow{6}{*}{$\mathrm{C}_{2} \mathrm{H}_{2}$} & 800 & 10 & 10 & \multirow{6}{*}{1.0} & \\
\hline$A_{2}$ & & 750 & 10 & 10 & & 20 \\
\hline$A_{3}$ & & 725 & 10 & 10 & & 10 \\
\hline$A_{4}$ & & 700 & 10 & 10 & & 60 \\
\hline$A_{5}$ & & 650 & 10 & 10 & & 10 \\
\hline$A_{6}$ & & 500 & 10 & 10 & & 10 \\
\hline
\end{tabular}

новившимися температурными и газо-кинетическими условиями [10,11]. Образование наночастиц железа из каталитического прекурсора - хлорида железа (III) происходит при его термическом разложении в процессе синтеза. После окончания синтеза печь выключается, а УСП и восстановитель заменяются на аргон: таким образом, образец медленно остывает вместе с печью в атмосфере аргона.

Основные параметры проведенных нами экспериментов сведены в таблицу. Каждому образцу присвоено буквенное обозначение в соответствии с использованным УСП („ $M “$ для метана, „A“ для ацетилена) и порядковый номер. Ячейки, содержащие номера тех образцов, в которых, согласно последующим исследованиям, не было зафиксировано образования УНТ, выделены серым цветом. Для образцов $M_{6}-M_{8}$ и $A_{2}-A_{6}$ также проводился предварительный отжиг подложки с нанесенным на нее каталитическим прекурсором в атмосфере водорода в течение $15 \mathrm{~min}$, непосредственно предшествовавших фазе синтеза.

Спектры комбинационного рассеяния света (КРС) образцов (в диапазоне $50-3200 \mathrm{~cm}^{-1}$ ) возбуждались излучением $\mathrm{Ar}^{+}$лазера с длиной волны $\lambda=514.5 \mathrm{~nm}$ и регистрировались в геометрии обратного рассеяния спектрометром Renishaw inVia Reflex, оснащенным CCD-детектором. Морфология образцов изучена при помощи сканирующего электронного микроскопа Zeiss SUPRA 25. 


\section{2. Результаты и обсуждение}

На пяти из шести синтезированных из ацетилена образцов $\left(A_{1}-A_{5}\right)$ по микрофотографиям, выборочно представленным на рис. 1, наблюдается образование многостенных углеродных нанотрубок (МУНТ) и их пучков, что также подтверждается данными спектроскопии КРС, которые будут подробно рассмотрены ниже. Зарегистрировать рост УНТ, синтезированных с использованием метана (рис. 2), удалось для всех образцов, кроме $M_{8}$ и $M_{9}$. Вероятно, условия синтеза образца $M_{7}$ являются „Пороговыми“ для получения УНТ при низких давлениях в рамках используемой нами методики.

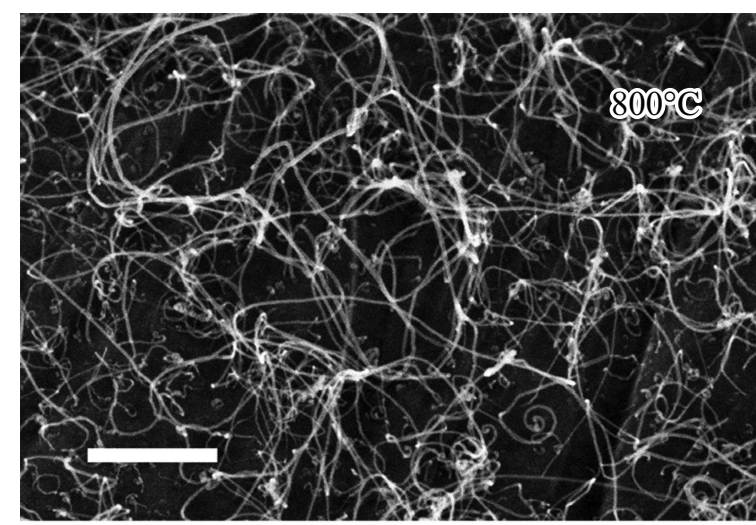

$a$
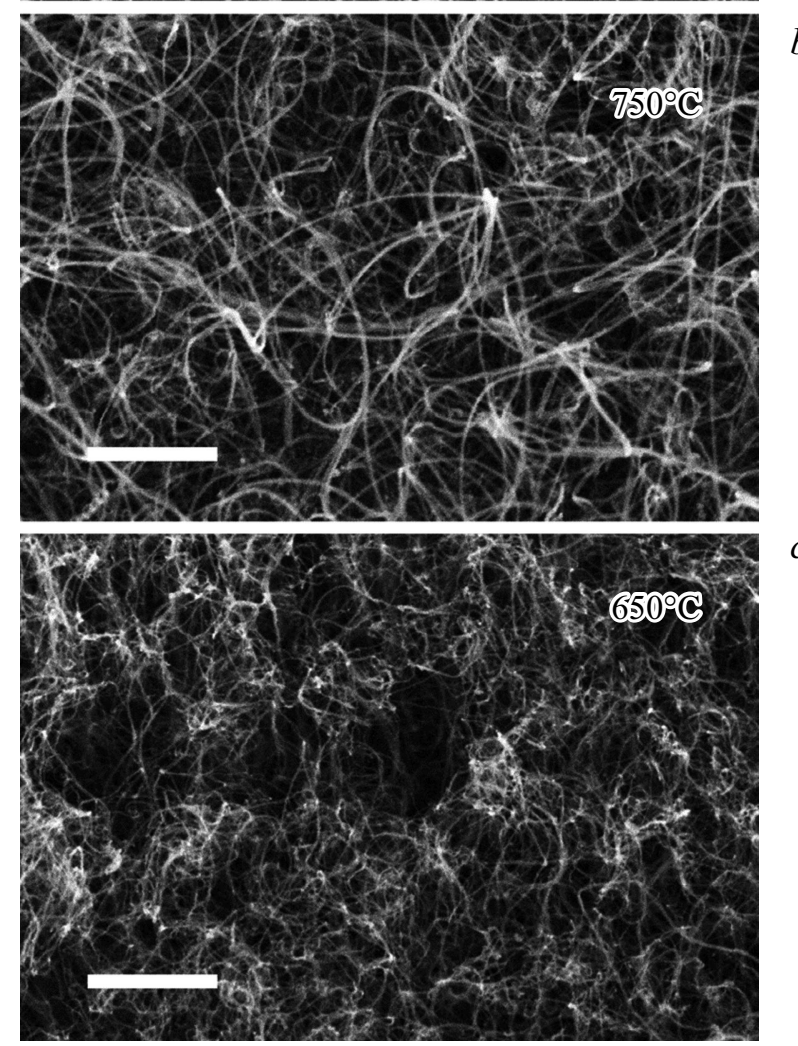

Рис. 1. СЭМ изображения образцов, синтезированных из ацетилена. Во время фазы синтеза потоки газов составляли для $\mathrm{C}_{2} \mathrm{H}_{2}$ и $\mathrm{H}_{2}$ по $10 \mathrm{sccm}$, давление - 1 Torr. Значения температур указаны на изображениях, масштабный отрезок на каждом соответствует $500 \mathrm{~nm}$.


Рис. 2. СЭМ изображения образцов, синтезированных из метана. Во время фазы синтеза для двух образцов $(a, b)$ потоки газов составляли $\mathrm{CH}_{4}-100 \mathrm{sccm}$ и $\mathrm{H}_{2}-200 \mathrm{sccm}$, давление -760 Torr, для третьего образца $(c) \mathrm{CH}_{4}$ и $\mathrm{H}_{2}-$ по $50 \mathrm{sccm}$, давление - 10 Torr. Температуры синтеза указаны на изображениях, масштабный отрезок на каждом соответствует $500 \mathrm{~nm}$.

Предварительный отжиг подложки с нанесенным на нее каталитическим прекурсором в атмосфере водорода в течение $15 \mathrm{~min}$ привел к меньшей агломерации частиц катализатора и увеличению плотности роста УНТ (рис. 2,c). Из микрофотографий произведена оценка диаметров УНТ: для образцов $M_{2}-M_{7}, A_{1}-A_{5}$ они лежат в диапазоне 5-45 nm. В образце $M_{1}$ наблюдаются более толстые УНТ - до 60-90 nm в диаметре.

Необходимо отметить, что плотность, характер и морфология распределения УНТ по поверхности подложки 
для образцов, синтезированных из разных УСП, отличаются существенно. Полученные из ацетилена УНТ на размерном уровне $\sim 1 \mu \mathrm{m}$ покрывают поверхность подложки практически однородно, демонстрируя весьма существенные радиусы изгиба, вплоть до закручивания в спирали. При этом они в весьма малой степени агломерируют друг с другом. Синтезируемые из метана УНТ, напротив, распределены неоднородно - присутствуют области со скоплениями и участки с малой плотностью УНТ (рис. 2, $a, b)$, длина которых многократно превосходит размерный уровень $1 \mu \mathrm{m}$, а радиусы искривления трубок малы.

Спектры КРС образцов $A_{1}-A_{5}$ являются типичными для МУНТ, включая в себя $D-, G-, D^{\prime}-$ и $2 D$-области на частотах около $1350,1580,1620$ и $2700 \mathrm{~cm}^{-1}$ соответственно [12], а также радиальные дыхательные моды (radial breathing modes - RBM) в диапазоне $50-300 \mathrm{~cm}^{-1}$. Пример одного из спектров приведен на рис. 3. Как хорошо известно, радиальные дыхательные моды являются отличительной особенностью УНТ, представляя собой синхронное смещение атомов углерода в нанотрубке в радиальном направлении. $G$ мода происходит из центра зоны Бриллюэна графенового листа и представляет собой валентные колебания атомов углерода в его плоскости, наблюдаясь с теми или иными особенностями для всех $s p^{2}$-углеродных систем. Остальные моды соответствуют процессам двойного резонанса и связаны с точками $K$ обратного пространства графенового листа, представляя собой „дыхательные“ колебания гексагонов в его плоскости. $D$ - и $D^{\prime}$-моды (запрещенные для идеальных $s p^{2}$-углеродных структур) активируются в присутствии различных дефектов (вакансий, границ, $s p^{3}$-связей с другими атомами), и поэтому могут быть связаны как с дефектами самих углеродных нанотрубок, так и присутствием в каждом образце некоторого количества аморфного углерода, отражая дефектность полученного углеродного наноматериала в целом. $2 D\left(G^{\prime}\right)$-мода, имеющая удвоенную по сравнению с $D$ частоту, наблюдается в спектре вне зависимости от присутствия в образце дефектов и является чувствительной к трехмерному упорядочению $s p^{2}$-углеродного материала.

Образцы $A_{6}$ и $M_{9}$ имеют спектры, типичные для аморфного углерода: очень широкие, сравнимые по пиковой интенсивности и перекрывающиеся друг с другом $D$ - и $G$-области сопровождаются размытым „куполом“ $2 D$-полосы, не имеющей четко выраженных интенсивных пиков [13]. С образца $M_{8}$ получить спектр КРС не удалось по причине сильной люминесценции. Поэтому данные образцы исключаются из дальнейшего рассмотрения.

Отличие спектров КРС образцов МУНТ $M_{1}-M_{7}$ заключается в том, что для них зачастую оказывалось возможным явно увидеть расщепление $G$-полосы на несколько компонент (рис. 4). Согласно литературным данным, для УНТ данное явление наблюдается нечасто $[14,15]$. Оно может быть связано как с выполне- нием условий резонансного рассеяния, так и с меньшей поверхностной плотностью УНТ. В нашем случае последнее предположение является более вероятным и подтверждается данными электронной микроскопии.

Каждый спектр образцов УНТ был разложен на составляющие компоненты при помощи функций Лоренца для случаев с явным спектральным расщеплением $G$-полосы, и функции Брейта-Вигнера-Фано (BWF) для случаев без такого расщепления и явной асимметрии спектрального профиля линий. Данный подход является одним из общепринятых в литературе для описания асимметричного профиля $G$-полосы без спектрального расщепления, обусловленного различными причинами [13]. В нашем случае наиболее вероятная причина высокая плотность распределения УНТ на подложке при синтезе из ацетилена. Пример подобного разложения спектра на составляющие компоненты с использованием функции BWF показан на рис. 3, аппроксимация спектра исключительно при помощи функции Лоренца представлена на рис. 4. После разложения спектров всех образцов данные, характеризующие $D$ - и $G$-области, были систематизированы: построены зависимости частот $D$ - и $G$-пиков, их ширин на половине максимальной высоты (full width at half maximum - FWHM), а также отношения пиковых $\left(I_{D} / I_{G}\right)$ и интегральных $\left(A_{D} / A_{G}\right)$ интенсивностей от температуры синтеза. В каждой из зависимостей (рис. 5) были проведены аппроксимационные кривые для более удобного и наглядного представления полученных результатов. Отдельно отметим, что во всех спектрах присутствует также до нескольких линий со спектральной шириной $5-10 \mathrm{~cm}^{-1}$ в диапазоне $50-300 \mathrm{~cm}^{-1}$, которые однозначно относятся к радиальным дыхательным модам УНТ.

Рассмотрим зависимости отношений $I_{D} / I_{G}$ и $A_{D} / A_{G}$ от температуры синтеза. Для образцов $A_{1}-A_{5}$ (рис. $\left.5, a\right)$ данные отношения имеют наибольшие значения при температурах 650 и $700^{\circ} \mathrm{C}$, значительно уменьшаясь с дальнейшим повышением температуры синтеза. Для образцов $M_{1}-M_{5}$ (рис. $\left.5, b\right)$ наблюдаемые зависимости несколько отличаются: на первый взгляд увеличение температуры приводит к увеличению отношения $I_{D} / I_{G}$, в то время как зависимость $A_{D} / A_{G}$ в области температур менее $1000^{\circ} \mathrm{C}$ в целом похожа на те, что приведены на рис. 5, $a$, с последующим резким возрастанием значения $A_{D} / A_{G}$ при $1050^{\circ} \mathrm{C}$. Хорошо известно, что в наиболее общем приближении отношения $I_{D} / I_{G}$ и $A_{D} / A_{G}$ характеризуют степень дефектности углеродного материала: чем меньше эти отношения, тем менее дефектны образцы [12]. Тем не менее существуют и более детальные объяснения наблюдаемого поведения рассматриваемых зависимостей. В частности, авторы [16] вводят понятия структурно разупорядоченной и активированной областей. Первая область содержит дефект и вызванные им локальные искажения кристаллической структуры, вторая же находится вокруг первой, не претерпевая структурных изменений, однако, в силу непосредственной близости разупорядоченной области, 


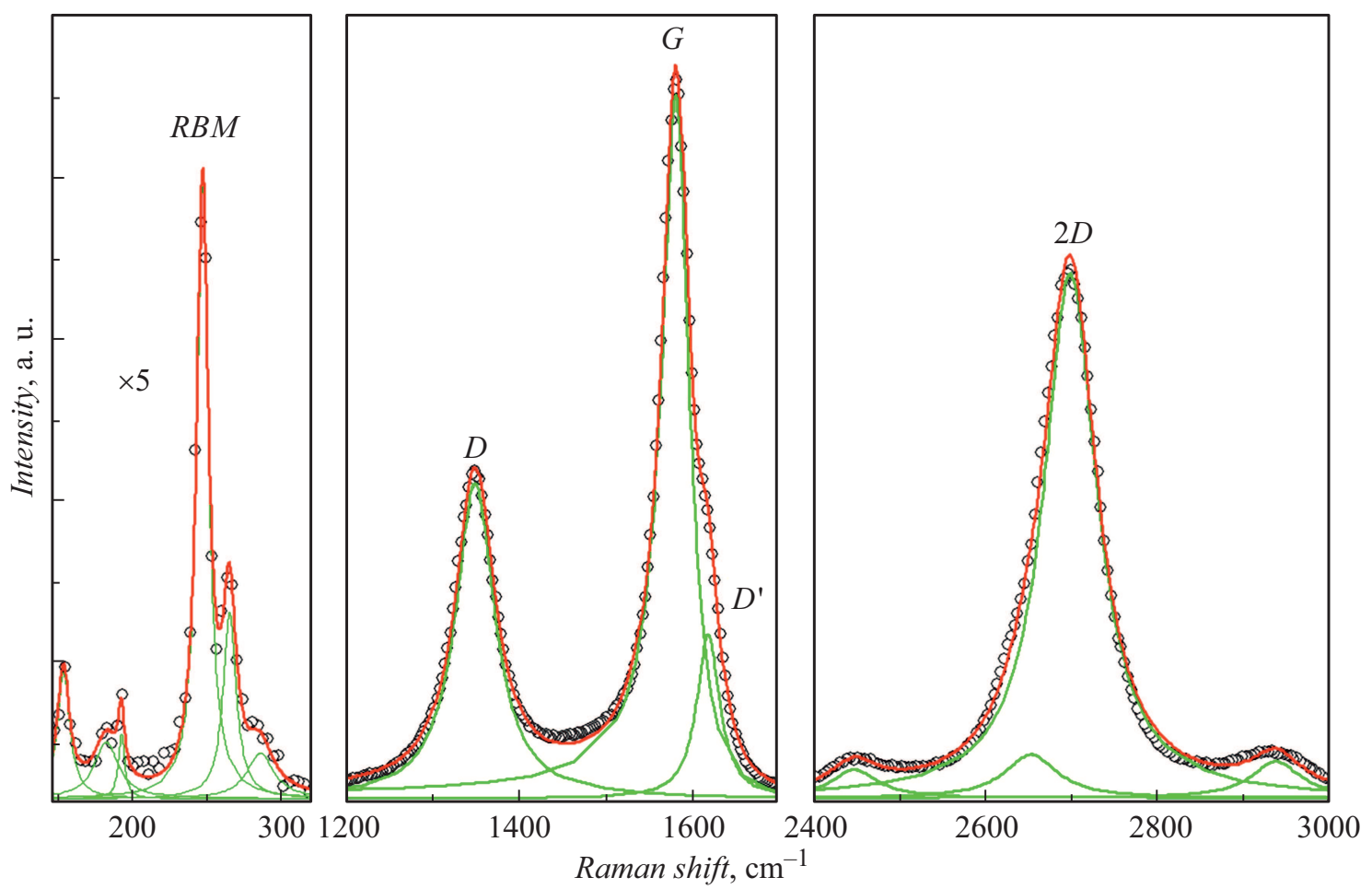

Рис. 3. Спектр комбинационного рассеяния света для образца УНТ $\left(A_{4}\right)$, синтезированного из ацетилена при температуре $700^{\circ} \mathrm{C}$, и его разложение на составляющие компоненты при помощи функций Лоренца и Брейта-Вигнера-Фано.

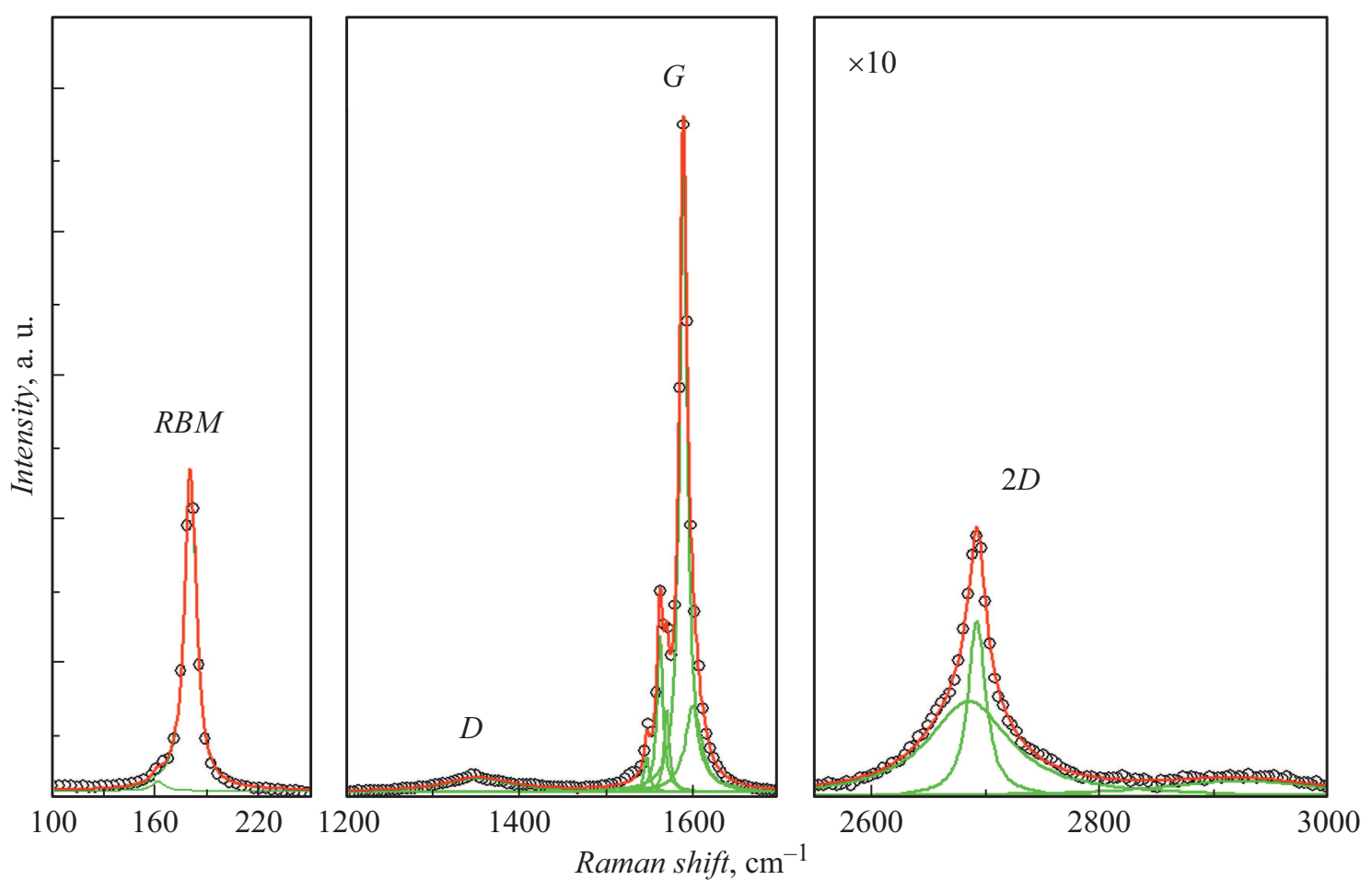

Рис. 4. Спектр комбинационного рассеяния света для образца УНТ $\left(M_{4}\right)$, синтезированного из метана при температуре $950^{\circ} \mathrm{C}$, и его разложение на составляющие компоненты при помощи функции Лоренца.

комбинационное рассеяние в ней будет также происходить с нарушением правил отбора, т.е. с активацией $D$-моды. При этом вклад в интенсивность комбинаци- онного рассеяния первой области значительно меньше, чем аналогичный вклад второй, поскольку в структурно разупорядоченной области нарушается кристаллическая 

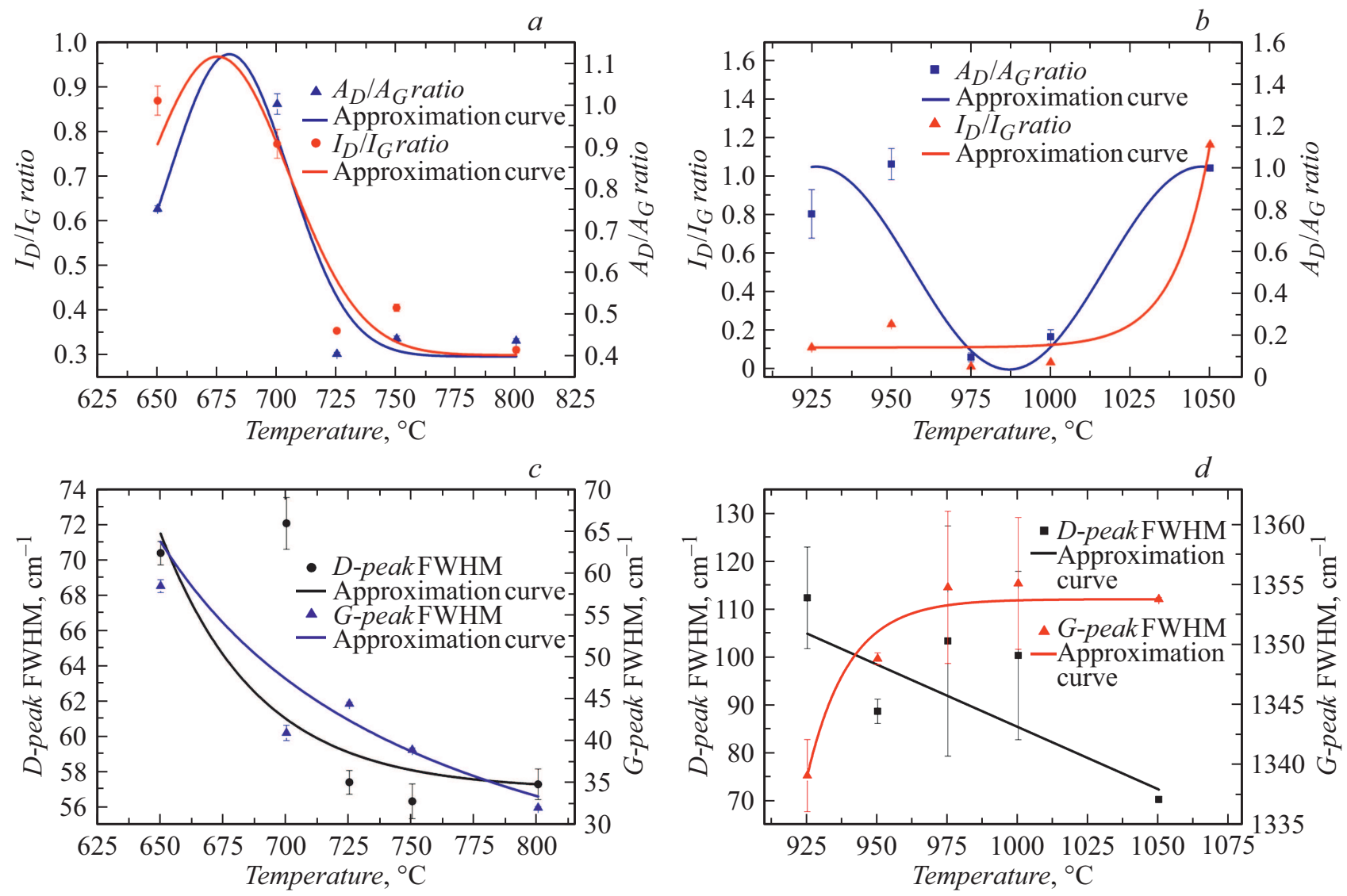

Рис. 5. Данные спектроскопии КРС и их обработка для образцов $A_{1}-A_{5}$ и $M_{1}-M_{7}$ : зависимости от температуры синтеза $I_{D} / I_{G}$ и $A_{D} / A_{G}$ для $A_{1}-A_{5}(a)$ и $M_{1}-M_{5}(b)$, FWHM $D$ - и $G$-пиков для $A_{1}-A_{5}(c)$, FWHM и частот $D$-пика для $M_{1}-M_{5}(d)$.

структура образца как таковая. Поэтому увеличение количества дефектов сначала приводит к увеличению суммарной площади как структурно разупорядоченных областей, так и активированных. Следовательно, увеличивается и интенсивность $D$-моды. Однако после определенного порога площадь структурно упорядоченных областей начинает существенно превышать площадь активированных, что приводит к уменьшению интенсивности $D$-моды. Следует отметить, что приведенная в работе [16] зависимость отношения $I_{D} / I_{G}$ от расстояния между дефектами имеет вид, аналогичный полученным нами зависимостям для $I_{D} / I_{G}$ и $A_{D} / A_{G}$ от температуры синтеза образцов $A_{1}-A_{5}$ (при $T=650-800^{\circ} \mathrm{C}$ ) и $M_{2}-M_{5}\left(T=925-1000^{\circ} \mathrm{C}\right)$. В силу этого описанное выше пороговое значение расстояния между дефектами можно получить при температуре синтеза в интервалах $650-700$ и $925-950^{\circ} \mathrm{C}$ для ацетилена и метана в качестве УСП соответственно. Более высокие температуры синтеза ведут как к уменьшению количества дефектов, так и к увеличению расстояния между ними. Что касается резкого увеличения отношений $I_{D} / I_{G}$ и $A_{D} / A_{G}$ для образца $M_{1}$, оно может коррелировать с наблюдаемым на снимках СЭМ существенным утолщением МУНТ по сравнению со всеми остальными образцами, и, как следствие, резким увеличением суммарной площади активированных областей, а не плотности дефектов.

Теперь рассмотрим зависимости величины FWHM Dи $G$-пиков. С ростом температуры синтеза для образцов $A_{1}-A_{5}$ данные зависимости носят экспоненциально убывающий характер (рис. $5, c$ ), а для образцов $M_{1}-M_{5}$ заметно изменяется только ширина $D$-пика, также уменьшаясь при увеличении температуры (рис. 5, $d$, черные точки и линия). Наблюдаемое явление можно объяснить следующим хорошо известным фактом [12]: беспорядок, вносимый случайным распределением дефектов, вызывает уширение комбинационных мод, т.е. более дефектные материалы обладают большим значением FWHM, что подтверждает сделанный выше вывод о том, что рост температуры синтеза приводит к уменьшению количества дефектов в образцах, а увеличение значений $I_{D} / I_{G}$ и $A_{D} / A_{G}$ для образца $M_{1}$ связано с существенным утолщением МУНТ, а не с увеличением плотности дефектов.

Увеличение температуры синтеза также оказывает влияние на частоты $D$ - и $G$-мод. В образцах $A_{1}-A_{5}$ положение $D$-пика претерпевает лишь незначительные изменения в пределах $\pm 1.5 \mathrm{~cm}^{-1}$ от среднего значения в $1346 \mathrm{~cm}^{-1}$. Частота $G$-моды, напротив, изменяется заметно, уменьшаясь на $8 \mathrm{~cm}^{-1}$ с увеличением темпе- 
ратуры синтеза. И поскольку частота $G$-моды напрямую зависит от длины связи $\mathrm{C}-\mathrm{C}$, наблюдаемое явление может иметь несколько возможных объяснений. Вопервых, длина связи С-C чувствительна к изменению межслоевого расстояния в МУНТ $[17,18]$ : чем меньше межслоевое расстояние, тем выше оказывается частота $G$-моды. Во-вторых, влияние на связь С-C также может оказываться посредством допирования $[14,19,20]$ и явления переноса заряда [21], что в нашем случае может происходить за счет частиц катализатора. В-третьих, хорошо известно явление, когда взаимодействие между $G$-фононом и экситонами вблизи точки $K$ обратного пространства нанотрубки приводит к сдвигу $G$-моды в область более низких частот для металлических нанотрубок [22]. Возможно, что изменение температуры синтеза влияет на тип проводимости слоев, образующихся из ацетилена нанотрубок, что отражается на величине экситон-фононного взаимодействия и, как следствие, частоте $G$-моды. Разумеется, установить, какой именно фактор является решающим для рассматриваемых нами образцов, на текущий момент не представляется возможным.

Наконец, в спектрах КРС образцов $M_{2}-M_{5}$ наблюдается явное расщепление $G$-полосы на несколько компонент, положение и ширина которых не демонстрируют никаких явно выраженных зависимостей. Спектр образца $M_{1}$ имеет широкую $\left(\sim 70 \mathrm{~cm}^{-1}\right)$ и асимметричную $G$-полосу, напоминая спектры $A_{1}-A_{5}$. Что касается $D$ полосы для образцов $M_{1}-M_{5}$, то ее ширина с ростом температуры синтеза уменьшается (рис. $5, d$, черные точки и прямая), как и в случае описанных выше образцов $A_{1}-A_{5}$. В свою очередь, частота $D$-полосы увеличивается с ростом температуры синтеза (рис. $5, d$, красные точки и кривая (в on-line версии)). В случае постоянной длины волны возбуждающего излучения данный факт принято главным образом связывать с изменением типа допирующих примесей в углеродном наноматериале: значительное смещение $D$-моды в сторону более низких частот говорит о допировании $n$-типа, в сторону более высоких о примесях $p$-типа $[14,23]$, что в нашем случае также может происходить за счет взаимодействия МУНТ с частицами катализатора. Следует отметить, что большие погрешности в определении характеристик $D$-моды для некоторых образцов, полученных из метана (рис. $5, d$ ), объясняются ее профилем: в соответствующих спектрах она имеет низкую интенсивность и значительную ширину (как на рис. 3), что затрудняет точное определение как ее ширины, так и частотного положения.

\section{Заключение}

Таким образом, в работе был предложен простой и гибкий способ синтеза МУНТ методом каталитического химического осаждения из газовой фазы. Показано, что для получения МУНТ при одном и том же катализаторе $\mathrm{FeCl}_{3}$, а также одинаковом способе его подготовки и нанесения на подложку, при переходе между двумя разными УСП (метаном и ацетиленом) требуются лишь определенные изменения температуры и скорости потока прекурсора. Длительность синтеза можно ограничить даже $10 \mathrm{~min}$ - этого времени оказывается достаточно для выращивания МУНТ длиной в десятки $\mu \mathrm{m}$. Исследование образцов с помощью СЭМ и спектроскопии КРС позволило показать влияние температуры синтеза на морфологию образцов, дефектность УНТ и параметры спектров их КРС. Установлено, что предварительный отжиг подложки с нанесенным на нее каталитическим прекурсором в атмосфере водорода в течение $15 \mathrm{~min}$ приводит к меньшей агломерации частиц катализатора и увеличению плотности роста МУНТ на поверхности подложки. Выявлено, что понижение температур приводит к значительному увеличению дефектности синтезируемых из ацетилена УНТ. Напротив, для синтеза УНТ из метана необходим больший расход газов и более высокие температуры, однако таким путем можно получить низкую дефектность образцов.

\section{Благодарности}

Авторы выражают благодарность к.ф.-м.н. Левшову Д.И. за помощь в обсуждении результатов по спектроскопии комбинационного рассеяния света.

\section{Финансирование работы}

Работа выполнена при поддержке Российского фонда фундаментальных исследований в рамках проекта № 1829-19043 мк.

\section{Конфликт интересов}

Авторы заявляют, что у них нет конфликта интересов.

\section{Список литературы}

[1] R.H. Baughman, A.A. Zakhidov, W.A. De Heer. Science, 297 (5582), 787 (2002). DOI: 10.1126/SCIENCE. 1060928

[2] M.F.L. De Volder, S.H. Tawfick, R.H. Baughman, A.J. Hart. Science, 339 (6119), 535 (2013). DOI: $10.1126 /$ SCIENCE.1222453

[3] Y. Li. ACS Nano, 11 (1), 1 (2017). DOI: $10.1021 / A C S N A N O .7 B 00232$

[4] R. Rao, C.L. Pint, A.E. Islam, R.S. Weatherup, S. Hofmann, E.R. Meshot, F. Wu, C. Zhou, N. Dee, P.B. Amama, J. Carpena-Nuñez, W. Shi, D.L. Plata, E.S. Penev, B.I. Yakobson, P.B. Balbuena, C. Bichara, D.N. Futaba, S. Noda, H. Shin, K. Su Kim, B. Simard, F. Mirri, M. Pasquali, F. Fornasiero, E.I. Kauppinen, M. Arnold, B.A. Cola, P. Nikolaev, S. Arepalli, H.-M. Cheng, D.N. Zakharov, E.A. Stach, J. Zhang, F. Wei, M. Terrones, D.B. Geohegan, B. Maruyama, S. Maruyama, Y. Li, W.W. Adams, A.J. Hart. ACS Nano, 12 (12), 11756 (2018). DOI: $10.1021 /$ ACSNANO.8B06511

[5] V. Jourdain, C. Bichara. Carbon, 58, 2 (2013). DOI: 10.1016/J.CARBON.2013.02.046 
[6] J. Prasek, J. Drbohlavova, J. Chomoucka, J. Hubalek, O. Jasek, V. Adamc, R. Kizek. J. Mater. Chem., 21 (40), 15872 (2011). DOI: $10.1039 / \mathrm{C} 1 \mathrm{JM} 12254 \mathrm{~A}$

[7] M. Cantoro, S. Hofmann, S. Pisana, V. Scardaci, A. Parvez, C. Ducati, A.C. Ferrari, A.M. Blackburn, K.-Y. Wang, J. Robertson. Nano Lett., 1107 (2006). DOI: $10.1021 / \mathrm{n} 1060068 \mathrm{y}$

[8] D.N. Futaba, K. Hata, T. Namai, T. Yamada, K. Mizuno, Y. Hayamizu, M. Yumura, S. Iijima. J. Phys. Chem. B, 110 (15), 8035 (2006). DOI: 10.1021/JP060080E

[9] F. Yang, X. Wang, D. Zhang, J. Yang, D. Luo, Z. Xu, J. Wei, J.-Q. Wang, Z. Xu, F. Peng, X. Li, R. Li, Y. Li, M. Li, X. Bai, F. Ding, Y. Li. Nature, 510 (7506), 522 (2014). DOI: $10.1038 /$ NATURE13434

[10] X. T. Than. Univ. Montpellier II 2011. Available: http://www.theses.fr/2011MON20110.

[11] B.T. Nguyen, X.T. Than, V.C. Nguyen, T.T. Tam Ngo, H.T. Bui, X.N. Nguyen, H.K Phan, N.M. Phan. Adv. Nat. Sci. Nanosci. Nanotechnol., 3 (2), (2012). DOI: $10.1088 / 2043-6262 / 3 / 2 / 025010$

[12] R. Saito, M. Hofmann, G. Dresselhaus, A. Jorio, M.S. Dresselhaus. Adv. Phys., 60 (3), 413 (2011). DOI: $10.1080 / 00018732.2011 .582251$

[13] A.C. Ferrari, J. Robertson. Phys. Rev. B, 31 (2), 632 (2011). DOI: $10.1007 / \mathrm{BF} 02543692$

[14] H. Murphy, P. Papakonstantinou, T.I.T. Okpalugo. J. Vac. Sci. Technol. B Microelectron. Nanom. Struct, 24 (2), 715 (2006). DOI: $10.1116 / 1.2180257$

[15] X. Zhao, Y. Ando, L.C. Qin, H. Kataura, Y. Maniwa, R. Saito. Appl. Phys. Lett., 81 (14), 2550 (2002).

DOI: $10.1063 / 1.1502196$

[16] M.M. Lucchese, F. Stavale, E.H. Martins Ferreira, C. Vilani, M.V.O. Moutinho, R.B. Capaz, C.A. Achete, A. Jorio. Carbon N.Y., $48(5), 1592$ (2010).

DOI: 10.1016/J.CARBON.2009.12.057

[17] B.P.M. Ajayan, L.S. Schadler, C. Giannaris, A. Rubio. Adv. Mater., (10), 750 (2000).

[18] V.N. Popov, D.I. Levshov, J.L. Sauvajol, M. Paillet. Phys. Rev. B, 97 (16), 1 (2018). DOI: 10.1103/PHYSREVB.97.165417

[19] H. Shiozawa, T. Pichler, A. Grüneis, R. Pfeiffer, H. Kuzmany, Z. Liu, K. Suenaga, H. Kataura. Adv. Mater., 20 (8), 1443 (2008). DOI: 10.1002/ADMA.200701466

[20] H. Shiozawa, T. Pichler, C. Kramberger, A. Grüneis, M. Knupfer, B. Büchner, V. Zólyomi, J. Koltai, J. Kürti, D. Batchelor, H. Kataura. Phys. Rev. B, 77 (15), 3 (2008). DOI: 10.1103/PHYSREVB.77.153402

[21] V. Zólyomi, J. Koltai, Á. Rusznyák, J. Kürti, Á. Gali, F. Simon, H. Kuzmany, Á. Szabados, P.R. Surján. Phys. Rev. B, 77 (24), 1 (2008). DOI: 10.1103/PHYSREVB.77.245403

[22] H. Farhat, H. Son, G.G. Samsonidze, S. Reich, M.S. Dresselhaus, J. Kong. Phys. Rev. B, 99 (14), 1 (2007). DOI: 10.1103/PHYSREVLETT.99.145506

[23] J. Liu, Q. Li, Y. Zou, Q. Qian, Y. Jin, G. Li, K. Jiang, S. Fan. Nano Lett., 13 (12), 6170 (2013). DOI: 10.1021/NL4035048 